\title{
Scaffolding Based on Cognitive Conflict in Correcting the Students' Algebra Errors
}

\author{
Indah Puspitasari Maharani ${ }^{1 *}$, Subanji Subanji ${ }^{1}$ \\ ${ }^{1}$ State University of Malang, INDONESIA

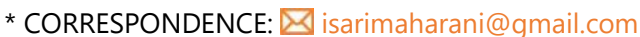

\begin{abstract}
The purpose of the research is to describe and analyze the implementation of Scaffolding based on Cognitive Conflict in correcting the students' errors in Algebra material. The research uses Mix Method, that is a combination of quantitative and qualitative methods. There are 25 students that are involved and tested on Algebra material. They are collected from the Second Grade Students of Junior High Schools in Malang. The quantitative data are collected through essay test, while the qualitative data are collected through interview and observation. The findings of the research are: (1) Cognitive Conflict can increase the students' reasoning ability, (2) Scaffolding is required to overcome the students' errors based on their Cognitive Conflict, (3) Cogtnitive Conflict needs to be improved in the classroom learning.
\end{abstract}

Keywords: scaffolding, cognitive conflict, algebra errors

\section{INTRODUCTION}

The term of Cognitive Conflict is proposed by Piaget as a Psychological Development and is an important factor in cognitive change (Lee et al, 2003; Bao et al, 2013). Piaget explains that every individual who learn to build their own personal theories and adapt it through assimilation process and accommodation from the learning experience. Assimilation refers to the acceptance of the new ideas, while accomodation relates to the students' modification in organizing their new ideas into the existing conceptual framework (Limon, 2001; Posner, 1982; Santrock, 2012).

In the learning process, cognitive conflict occurs when the students are given an unusual new situation with what they learn. Students will mentally build a new situation from their initial knowledge and build an expectation of what happens from the situation. Students comfortably assimilate when their expectations are the same, but when the inconsistent and contradiction occur they will feel confused, disappointed, surprised, or anxious (Sutopo, 2014). In addition, Dahlan (2014) states that the teachers need to decrease the students' disequilibration by using Scaffolding in order to motivate the students to review, examine, characterize the causes of inconsistency. It is the situation that will lead the students to change the recognition pattern into an accomodated knowledge and create the equlibration. Equilibration refers to the activity in eliminating the confusion (Swan et al, 2006).

Connected to the Piaget's theory (Limon, 2001) in describing the equilibration process, the responses to the cognitive are divided into two categories: adapted and unadapted responses. The unadapted responses are responses from the student who is unaware of the conflict. On the other hand, the adapted responses are classified into three types: 1) alpha, in this category the students ignore or do not take into account any conflict

\footnotetext{
Article History: Received 22 March 2018 • Revised 15 May $2018 \bullet$ Accepted 26 May 2018

(C) 2018 The Author(s). Open Access terms of the Creative Commons Attribution 4.0 International License (http://creativecommons.org/licenses/by/4.0/) apply. The license permits unrestricted use, distribution, and reproduction in any medium, on the condition that users give exact credit to the original author(s) and the source, provide a link to the Creative Commons license, and indicate if they made any changes.
} 
Table 1. The responses toward the anomalous data at the level of information process (adapted from Limon, 2001)

\begin{tabular}{cccc}
\hline \multicolumn{2}{c}{$\begin{array}{c}\text { Piaget: The responses toward the anomalous } \\
\text { data }\end{array}$} & $\begin{array}{c}\text { Chin and Brewer: The level of } \\
\text { conceptual change }\end{array}$ & $\begin{array}{c}\text { Chan: The level of knowledge } \\
\text { processing activities }\end{array}$ \\
\hline $\begin{array}{c}\text { The responses do not } \begin{array}{c}\text { The unawareness of } \\
\text { adjust }\end{array} \\
\text { contradictions }\end{array}$ & $\begin{array}{c}\text { There is no conceptual change Tidak } \\
\text { ada perubahan konseptual }\end{array}$ & Sub assimilation \\
\hline $\begin{array}{c}\text { The responses adjust } \\
\text { the awareness of } \\
\text { contradictions) }\end{array}$ & Alpha & $\begin{array}{c}\text { There is no conceptual change, yet } \\
\text { there is an awareness of contradiction }\end{array}$ & $\begin{array}{c}\text { Direct asimilation (constructive } \\
\text { surface) }\end{array}$ \\
\cline { 2 - 5 } & Gamma & The restructurisation is weak & $\begin{array}{c}\text { Development of the implicit } \\
\text { knowledge }\end{array}$ \\
\hline
\end{tabular}

in the data, 2) beta, in this category the students give a response by generalizing or differentiating the explanations, 3) gamma, in this category the students give a response by modifying the core of the problem.

Furthermore, Chan et al (Limon, 2001) explains that there are two main approaches in the process of contradictory information: 1) direct asimilation, it involves the adjustment of new infomation to what has been known, and 2) knowledge building, it involves a treatment toward the new information that needs to be explained. The treatment itself consists of five stages as described on Table 1.

Stage (1) Sub assimilation, a condition when the new information is reacted at the associative level; (2) Direct assimilation, a condition when the new infomation is assimilated as it if were already known or excluded as it is not appropriate with the previous beliefs, the new information may be ignored, rejected, excluded or distorted to make it appropriate with the previous beliefs; (3) Constructive surface, a condition when the new infomation is accepted, but the implication of one's beliefs are not considered. There is no integration of naive ideas with the new infomation. The new ideas can be considered as an extraordinary cases which do not involve a review of one's beliefs or ideas; (4) Development of the implicit knowledge, a condition when the new information is treated as something problematic that needs to be explained; and (5) Development of the explicit knowledge, a condition when the new infomation is accumulated to build a coherence in the domain understanding.

The cognitive development is characterized by the expansion of balance as explained by Piaget that it's development is signed as an increasing range of inconsistencies that can be eliminated by the students (Druyan, 1997). In addition, Adey and Shayer (Swan, 2006) build a program that is called Cognitive Acceleration Through Science Education (CASE) and Cognitive Acceleration Through Mathematics Education (CAME) as one of learning design whivh has four stages: 1) Concrete preparation, the activities to introduce the context of the problem and it's relationship with the initial knowledge; 2) Cognivtive conflict, the problem is presented at the level to challenge the students beyond just engaging their knowledge; 3) Metacognition, the students are encouraged to explain what they think, difficulties, mistakes, and how to correct it; 4) Bridging, the explicit activities are introduced to transfer the thinking strategies into the new situations. This learning involves a cognitive conflict based on Piaget's formal operationa (such as the idea of controlling the variables systematically).

Algebra is one of the most abstract strands in Mathematics and considered difficult (Egodawatte and Stoilescu, 2015). The fundamental difficulty for the students to learn Algebra is the use of symbolic language. Wagner and Parker (1999) highlight that the use of two different symbol systems (letters and numbers) at the same time in Algebra allows for confusion. They add that in the Algebra language, most of the linguistic difficulties relate to the variables and expressions as seen on the following example: the equation of $(2 x+4=4)$ is interpreted as $(2 x+2=4-2=2)$ and the most of translation difficulties occur in translating the word problem into the equation. Moreover, Perso (Toka, 2002) explain that the students' errors in the use of parentheses mean nothing for them, as seen on the following example: $2(a+b)=2 a+b$ happens in Algebra.

Sierpinska (2008) bears out a statement that the students do not have an adequate understanding toward the variables and they often think that letters are the names for the concrete objects based on their previous arithmetic knowledge. The use of symbols or letters to represent the numbers and expressions are the first difficulty for the students. Furthermore, Barrera, Medina, and Robayna (2004) classify the Algebraic errors into three sources: the appearance of Algebraic errors from arithmetoic, the use an inadequate procedural formula or rule (procedural errors), and the errors due to the nature of Algebra (structural errors).

Lee and Kwon (2003) show a model that can be used to overcome the Algebraic errors. The model itself has three stages: 1) The Initial stage, it is the stage before the Cognitive Conflict occur. It is included into the 
Table 2. The Indicators of the Students' Errors (\%)

\begin{tabular}{lcc}
\hline Indicators & Errors (\%) & Number \\
\hline Procedural & 36.6 & 8 \\
\hline Representation & 45.4 & 10 \\
\hline Modeling & 18.8 & 4 \\
\hline
\end{tabular}

process of existed belief/ conception and accept the new situations. At this stage, the conflict process is given to the students with some conditions: (a) recognized an anomolous situation (imbalance), (b) expressed the interest or anxiety in resolving the conflicts, (c) involved in the cognitive reassessment; 2) The Second stage (Cognitive Conflict), it is the stage where the students will utilize their cognitive ability in searching for the justification, confirmation, or verification toward their opinions. In this cognitive conflict situation, the students are able to gain the explainations from their environment, such as from teachers or Scaffolding. 2) The Third stage (Resolution Stage), it is the problem solving stage and also known as the stage of elimination of imbalance.

Syce (2009) has a point of view that in the stage of Cognitive Conflict, the teachers are able to provide a Scaffolding in the form of questions and encouragement to lead the students to think beyond their comfort zone. The questions may be more than one, and needs to be predicted what answers that will be given by the students. In addition, Anghileri (2006: 33) defines the Scaffoldding as a supportive learning technique that is given in a structured manner. It can be applied at the initial stage to encourage the students to learn independently. He proposes three Scaffolding levels as a set of teaching strategies that can be seen in the classroom. The most fundamental stage is the Environmental Provisions. The second stage is the Explaining, reviewing, and restructuring stage. The third stage is the Developing Conceptual Thinking stage, ie the teachers interactions are directed to develop the students' conceptual thinking.

It is crucial for the teachers to realize and analyze the students' difficulties in their learning process (Chick and Baker, 2005). The students' difficulties can be seen through the errors created by them in finishing their tests. The teachers' effort to find out the students' errors is useful to increase the students' achievement in learning mathematics. The contiuning errors will cause the lack of the students' understanding toward the next math topics and the accumulation of the students disabilities caused by the complexity of the problems in mastering the mathematical concepts and procedures.

\section{METHOD}

This research uses mix-method by giving the treatment to the research subjects in order to find out the effect and the description of the treatment (Creswell, 2010: 23). The quantitative data are collected through the initial tests in the form of the students' mathematical problems, then analyzed in the qualitative form.

The research is conducted in SMP LAB UM at the Second Grade classes consisting of 25 students. The place of the research is selected to examine the students' difficulties in finishing the Algebraic tests. To determine the sample of the research, the researcher take two students who experienced some errors in Algebra as the sample (research subject). The category is created based on the test results as well as the determination of the research subjects. The test instrument is created based on three main categories in Algebra: Algebraic expressions, representations, and models. The data of the research are the written and verbal data. The written data refers to the test results, on the other hand the verbal data refers to the interview results. The instrument used in this research are the Algebra tests and the interview guidelines. The procedures of data collection conducted by the research are the determining the research subjects, delivering the Algebra tests, and conducting the interview.

\section{FINDING AND DISCUSSION}

Based on the research that has been conducted in the school, the researcher will describe the findings that are collected from the subjects of the research. The research is based on the entire subjects that have been answered the questions and all of the possible answers are identified and recorded then categorized into the number of errors (\%). The answers given by the students through the tests show that they have low conceptual understanding and cause a lot of conceptual and procedural errors. The scores obtained by 25 students are $20 \%$ get $\geq 80$ (high), around $32 \%$ get $65-80$ (medium), and 48\% students get $\leq 64$ (low). Based on the scores, the researcher divides the students errors based on the category of indicators that are tested on Table 2. 
Table 2 shows that there are 3 students who do not answer, they are: 2 students do not answer to the procedural part, while 1 student does not answer to the representtaion part. Moreover, qualitative analysis is conducted to the students' works and interview results in order to identify the students' answers and errors in doing the tests given. The results of the tests show that there are many students who make mistake in answering the questions. Thus, the researcher take 2 samples randomly based on the mistake done by the students on the Algebra indicators that have been determined. In this case, the researcher take the procedural and representation indicators as the research material since those are the most common misconceptions occured. The interviews and it's analysis are described as follows:

\section{Problem 1}

Problem 1 refers to a procedural Algebra problem. According to Edogawate (2015), procedural knowledge is useful in maintaining the skills that are needed to solve the problems. In this test, the students are required to simplify the Algebraic form.

Find the simple form of: $\frac{x^{2}-y^{2}}{x-y}$

This test is chosen to involve the students in simplifying the common expression. Then, to see how the students can be careful in doing this. Also, to see whether the students noting that the rank involved is different in the way how to simplify it.

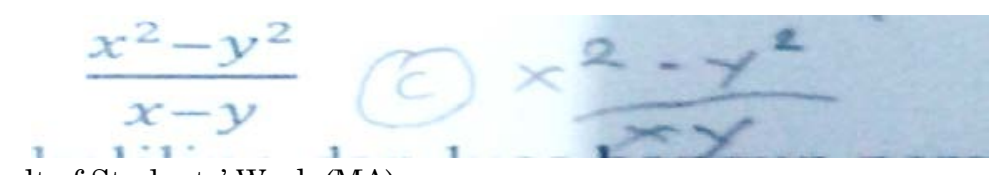

Picture 1. The Result of Students' Work (MA)

Generally, the form of mistake done by MA refers to his difficulty to simplify the fractional Algebraic operation especially in the writing of $x^{2}-y^{2}$ and $x y$. See the following identification toward the potential conflict that happened to MA.

$\mathrm{R} \quad$ : "Can you explain to me how you solved this problem 1 ?"

MA : "(MA) For this problem I only write $\mathrm{x}^{2}-\mathrm{y}^{2}=\mathrm{x}^{2}-\mathrm{y}^{2}$ and $\mathrm{xy} . "$

R : "How do you get $x y ? "$

MA : "I m confusing, Mom, I just guessed it becauase I have not understand about Algebra fragments, Mom. Is that true, Mom?"

R : "Please see it again. Do you understand about Algebraic multiplication in this problem?"

MA : "I do understand bout Algebraic multiplication, Mom. But, I have no idea about Algebraic fragments."

MA realizes that Algebraic fragmentsment he worked on is not correct because he only guessing the answer as seen in picture 1. Moreover, for the next step, cognitive conflict is given by giving the multiplication to the students.

$\mathrm{R} \quad$ : "In the case of $(2 \mathrm{x}+\mathrm{y}) \mathrm{x}(2 \mathrm{x}-\mathrm{y})$, how do you solve it?"

MA : "Mm... it is related to multiplication, Mom. $(2 \mathrm{x}+\mathrm{y})(2 \mathrm{x}-\mathrm{y})=4 \mathrm{x}^{2}+2 \mathrm{xy}-2 \mathrm{xy}-\mathrm{y}^{2}=4 \mathrm{x}^{2}-\mathrm{y}^{2}$ Mom."

R : "Well, can you see the equation of this problem? (pointing at the problem)."

MA : "Mm... (confusingion) I see the multiplication and the rank are the same, Mom."

R : "Can you explain it?"

MA : "Mm... the multiplication $(x+y)(x-y)=x^{2}+x y-x y-y^{2}=x^{2}-y^{2}$. Is that correct, Mom?" 


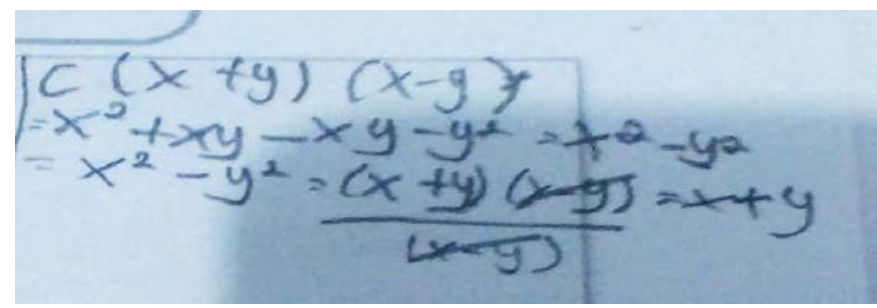

Picture 2. The Result of Students' Work (MA)

The cognitive conflict is useful to help the students in decreasing their confusing in learning. The test and interview result with] MA show that he is able to answer the problem by simplifying $x^{2}-y^{2}$ as a multiplication $(x+y)(x-y)$ so that the numerator and denominator can be simplified. It is because MA is able to understand the multiplication concept and keep trying. Overall, it indicated that MA is able to use his metacognition to solve the above problem after given the cognitive conflict in the form of multiplication. However, it is noted that the way he write the equation is need to be improved.

Overall, it is seen that MA is quite good in understanding the operation of Algebraic foems, but when given the Algebraic fractions he is still difficulty in doing it. Eventually, he only guesses the probability of the most correct answer. Based on the interview result, it can be seen that there is an effort done by MA to learn and to face the cognitive conflict given to him. MA uses direct assimilation toward his thinking and uses it into the Algebraic fractional procedures. He is sometimes hesitant in stating the operation he done since the previous concept he studied is different than the new one, especially after he is given the cognitive conflict and scaffloding.

\section{Problem 2}

Problem 2 refers to the Algebra problem that emphasizes the representation. Duval (2006) explain that mathematical representtaion is the most basic and old idea that represents an object, but at the same time this idea can be elusive or too formal.

"Please state the circumstance ad square are of the following area in the Algebraic form".

Problem in the form of Algebraic representation as a part of Algebraic learning. The form of the problem is chosen because the Algebraic representation has its own difficulties in reprenting it. The difficulty refers to the students problem in connecting the concept between variables and their representation forms of unkonwn from y. Here are the result of the student's work and interview related to this problem with MN.

At the beginning of the introduction, the form of mistake done by $\mathrm{MN}$ about Algebraic representation is he tries to represent by dividing the square into two parts, then represents it by writing his previous knowledge about square without seeing that it actualy has an Algebraic variable. Moreover, the researcher conducts the interviews to sind out the student' initial knowledge and conflict that may happend to MN. See the following interviews with $\mathrm{MN}$ :

R : "How bout this problem (pointing at the student's work on problem 2)"

MN : "Mm... that is confusing, Mom. Is gotten by dividing two rectangles, 1 and 2, but it is confusing, Mom."

R : "Why you are confused?"

MN : "If it is divided into two, how to write the score for $\mathrm{x}$ and $\mathrm{y}$ ?"

$\mathrm{R} \quad$ : "interesting ... just because of the score of $\mathrm{x}$ and $\mathrm{y}$ then you just write like this? (pointing at the student's answer). So, where do you get $\mathrm{K}=4 \times 1$ ?"

MN : "I do what I know, Mom. that is from the circumference of the square ie $4 \times \mathrm{s}$ and the large $\mathrm{s}$ $\times \mathrm{s}$ "

$\mathrm{R} \quad$ : "How about the score for $\mathrm{x}$ and $\mathrm{y}$ ?" (pointing at the problem)

MN : "mm ..." (silence) 


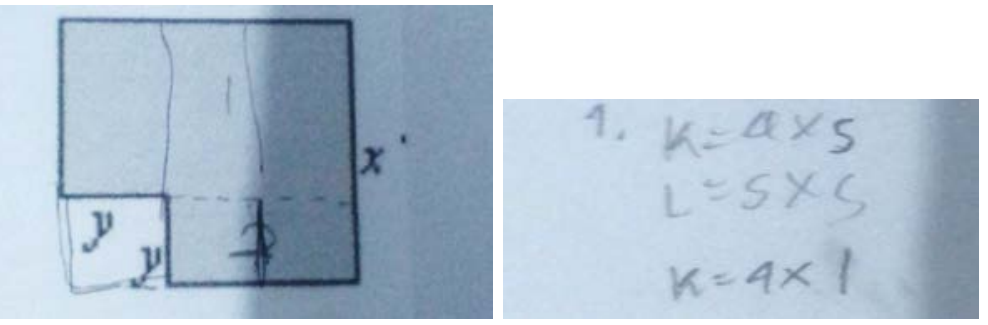

Picture 3. The Result of Students' Work (MN)

At the beginning of the introduction, MN has difficulty in writing the form of Algebraic representation. $\mathrm{MN}$ realizes the conflict by doing a direct assimilation related to what he knows without using an Algebraic representtaion to the related answer because he is still difficult to understand its writing (Limon, 2001). MN experiences a confusion and contradiction toward the square which is divided into two rectangular shapes and it is more confusing for him insolving the conflict. Furthermore, the assistance for the next step is given to $\mathrm{MN}$ in order to resolve the conflict that occur by using scaffolding in the form of directives and questions.

$\mathrm{R} \quad$ : "What do you know about the circumference of the square and the area?"

$\mathrm{MN}$ : "mm .... the square has a circumference $4 \times \mathrm{s}$ and the area is $\mathrm{s} \times \mathrm{s}$, Mom."

R : "Well, very good. Please see the following problem, how the sides?

MN : The side is $\mathrm{x}$, Mom. Oh beacuse it is square the the side is $\mathrm{x}$, Mom. Thus, if the square around is $4 \times \mathrm{s}$ equals with $4 \times x$ and the area $\mathrm{s} \times \mathrm{s}$ equals with $x \times x$, Mom..."

R : "Then, please see the following problem. How about this y side?"

MN : "I see it as an empty quare, Mom. If it is calculated the circumference of $4 \mathrm{y}$ and the area $\mathrm{y}^{2 "}$ (pause).

R : "Well, from here how is the score of circumference and the overall area of this square?"(pointing at the problem)

MN : (thinking) oh yeah the overal score of the large square minus the small square $4 \mathrm{x}-4 \mathrm{y}$ “

$\mathrm{R} \quad$ : and the area?"

MN : $x \times x$ and $\mathrm{y}^{2}$, Mom...

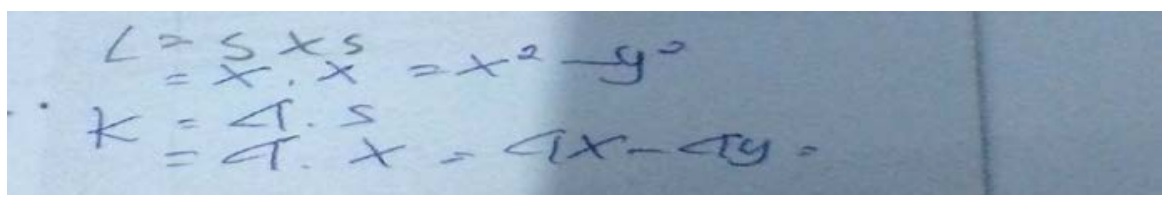

Picture 4. The Result of Students' Work (MN)

Generally, MN's initial work shows that he is still not well understand bout the concept. But, when he tries to explain, there is an indication that he does understand about the square concept but have not been able to apply it to the concept of Algebra. It is shown in the form of mistake when he tries to carry the variable $\mathrm{x}$ and $\mathrm{y}$ as the known sides. At this level, the cognitive conflict works on the assimilation where the student only uses the previous knowledge. Actually, MN realizes that the concept of Algebra is different, but he just can not write it properly. Thus, it is showed that the procedural knowledge is closely related to the concept and vice versa.

Moreover, the square that is written by $\mathrm{MN}$ in two rectangular forms indicates that he uses his metacognitive to accomodate his knowledge, but he is unable to represent it in Algebraic form. Then, to overcome the cognitive conflict, MN is given scaffolding in order to help him understand that a square can be formed into two rectangulars. However, he realizes that the whole shapes are squares with the circumference $4 \mathrm{x} \mathrm{s}$ and the area $\mathrm{s} \mathrm{s}$, then represents the into variables $\mathrm{x}$ and $\mathrm{y}$ in order to determine the circumference and the area of the related shapes.

Furthermore, on the problem 2 (picture 4), conceptually MN understand well on how to find a modified square by assuming the whole squares minus the empty square. In addition, based on the interview result, it is known that $\mathrm{MN}$ has understood well the concept of multiplication and how to represent the Algebra, but he 
is still mistaken in writing the results obtained, that is $\mathrm{L}=\mathrm{s} \mathrm{x} \mathrm{s}=x \times x=x^{2}-y^{2}$. During the learning process, $\mathrm{MN}$ tries to decrease his confusion or cognitive conflict by giving some questions.

\section{CONCLUSION}

Based on the research results, it is known that cognitive conflict plays an important role in changing the students' concept by examining the mistakes made by students (Zazkis and Chernoff, 2008). The new information that comes in conflict with the students' initial knowledge create an internal conflict for them. According to Piaget (Limon, 2001), the students' response to the conflict are varies, either by adapting to the problem or by not adapting to the problem. Especially in this research, the researcher takes into account the students' responses who adapt to the problem and find out the process of settlement in cognitive conflict with the of scaffolding.

Scaffolding given to the students aims to lead the students' initial knowledge in solving the problems encountered by them. The administration of scaffolding is different for each student. For example, student A only needs to recall his previous knowledge just because of he forget the material. While, student B needs an ongoing assistance until he can build his own knowledge.

In Algebra, the thinking processes are needed to understand the abstract part of Algebra which includes the Algebraic language and representation. The researcher finds out that the concept owned by the students are appropriate enough, but still needs to be guided in order to strengthen their understanding. It is because Algebra is very closely related in the mastery of another complex materials. Thus, the researcher suggests that during the learning process, teachers can apply the cognitive conflict to facilitate the students in mastery the Algebraic materials in the school and to lead the students to have a good critical thinking skills in learning.

\section{Disclosure statement}

No potential conflict of interest was reported by the authors.

\section{Notes on contributors}

Indah Puspitasari Maharani - State University of Malang, Indonesia.

Subanji Subanji - State University of Malang, Indonesia.

\section{REFERENCES}

Anghileri, J. (2006). Scaffolding Practices That Enhance Mathematics Learning. Journal of Mathematics Teacher Education, 9, 33-52. https://doi.org/10.1007/s10857-006-9005-9

Bao, L., Kim. Y., Raplinger, A., Han, J., \& Koenig, K. (2013). Affective Factors in STEM Learning and Scientific Inquiry: Assessment of Cognitive Conflict and Anxiety Special Issue of Research on Education Assessment and Learning. REAL: Research in Education Assessment and Learning Special Issue. Department of Physics, The Ohio State University.

Barrera, R. R., Medina, M. P., \& Robayna, M. C. (2004). Cognitive abilities and errors of students in secondary school in algebraic language processes. In D. E. McDougall \& J. A. Ross (Eds.), Proceedings of the Twentysixth Annual Meeting of the North American Chapter of the International Group for the Psychology of Mathematics Education, Vol 1 (pp. 253260). Ontario Institute for studies in Education, University of Toronto, Canada.

Chick, H. L., \& Baker, M. K. (2005). Investigating Teachers' Responses To Student Misconceptions. Proceedings Of The 29 Th Conference Of The International Group For The Psychology Of Mathematics Education, Vol. 2, pp. 249-256. Melbourne: Pme

Creswell, J. W. (2010). Research design: pendekatan kualitatif, kuantitatif, dan mixed. Yogjakarta: PT Pustaka Pelajar.

Dahlan, J. A., \& Rohayati, A. (2014). The Comparison Of Mathematical Understanding And Connection Through Cognitive Conflict Of Piaget And Hasweh. Proceeding of International Conference On Research, Implementation and Education of Mathematics And Sciences 2014, Yogyakarta State University, 18-20 May 2014. 
Duval, R. (2006). A Cognitive Analysis Of Problems Of Comprehension In A Learning Of Mathematics. Educational Studies In Mathematics, 61, 103-131. https://doi.org/10.1007/s10649-006-0400-z

Egodawatte, G., \& Stoilescu, D. (2015). Grade 11 Students' Interconnected Use Of Conceptual Knowledge, Procedural Skills, And Strategic Competence In Algebra: A Mixed Method Study Of Error Analysis. European Journal Of Science And Mathematics Education, 3, 289-305.

Limon, M. (2001). On The Cognitif Conflict As An Instructional Strategy For Conceptual Change: A Critical Appraisal. Learning And Instruction, 11(2001), 357-380. https://doi.org/10.1016/S0959-4752(00)000372

Posner, G. I., Strike, K. A., Hewson, P.W., \& Gertzog, W. A. (1982). Accommodation of a Scientific Conception: Toward a Theory of Conceptual Change. New York. Department Of Education Cornell University. Science Education, 211-227. CCC 0036-8326/82/020211-17502.70 https://doi.org/10.1002/sce.3730660207

Santrock, J. W. (2012). Life-Span Development (13th ed.). Translated by Benedictine Widyasinta. Erlangga dan Power Macro.

Sayce, L. (2009). The Route to Cognitive Conflict: A Planning Toolkit For Teachers. National Centre For Excellence In The Mathematics. The Project That Resulted In The Production Of This Document Was Jointly Funded By Reading Borough Council And The NCETM. It Was Completed In March 2009.

Sierpinska, A. 2008. Difficulties In learning Algebra. Diunduh. Retrieved from http://www.annasierpinska.wkrib.com/pdf/HongYueVanier111108.pdf

Susilawati, W., Suryadi D., \& Dahlan, J. A. (2017). The Improvement Of Mathematical Spatial Visualization Ability Of Student Through Cognitive Conflict. Iejme - Mathematics Education, 12(2), 155-166.

Sutopo, S. (2014). Counterexample In Cognitive Conflict As Factor Influencing Conceptual Change QIJIS: Qudus International Journal Of Islamic Studi, 2(2).

Swan, M., Wake, G., \& Joubert, M. (2006). Developing Conceptual understanding through Cognitive Conflict and Discussion in Mathematics and Science Education. Centre for Research in Mathematics Education University of Nottingham: FaSMEd Position Paper.

Toka, Y., \& Askar, P. (2002). The effect of cognitive conflict and conceptual change text on student's achievment related to first degree equation with one unknown. Hecettepe Universitise Kgitlan Fakkultesi Dergisi, 23, 211-217.

Wagner, S., \& Parker, S. (1999). Advancing Algebra. In. B. Moses (ed). Algebraic Thingking. Reston, VA. NCTM.

Zazkis, R., \& dan Chernoff, E. J. (2008). What makes a counterexample exemplary?. Faculty of Education, Simon Fraser University, Burnaby, BC V5A 1S6 Canada. Educ Stud Math, 68, 195-208. https://doi.org/10.1007/s10649-007-9110-4

Zetriuslita, Z., Wahyudin, W., \& Jarnawi, J. (2017). Mathematical Critical Thinking and Curiosity Attitude in Problem Based Learning and Cognitive Conflict Strategy: A Study in Number Theory course. International Education Studies, 10(7). https://doi.org/10.5539/ies.v10n7p65 